\title{
MANAGEMENT OF RHEUMATOID ARTHRITIS: SPECIAL CONSIDERATION FOR BIOLOGIC DISEASE-MODIFYING ANTIRHEUMATIC DRUGS
}

\author{
SALMI ABDUL RAZAK, MOHD MAKMOR-BAKRY, ADYANI MD-REDZUAN*
}

Faculty of Pharmacy, Universiti Kebangsaan Malaysia, Jalan Raja Muda Abdul Aziz, 50300 Kuala Lumpur, Federal Territory of Kuala Lumpur. Email: adyani@ukm.edu.my

Received: 14 June 2018, Revised and Accepted: 13 July 2018

\section{ABSTRACT}

Rheumatoid arthritis (RA) is a progressive chronic inflammatory disease affecting $0.5-1.0 \%$ of the adult population worldwide. Due to the damages caused by this autoimmune disease, new biologic therapies, particularly the biologic disease-modifying antirheumatic drugs (bDMARDs), are now being the treatment of choice in the management of RA. However, special precaution and prescreening before the usage of bDMARDs are needed to ensure better clinical response and avoiding risk of adverse event during treatment with the selected bDMARDs. In this review paper, we will provide overview on the incidence and pathogenesis of the disease, available pharmacological treatment and emphasizing special consideration in need on initiation of bDMARDs among RA patients. A literature review was performed by searching for relevant articles in Medline database through PubMed using medical subject headings terms and keywords: RA, bDMARDs, special consideration, tumor necrosis factor inhibitor, and non-tumor necrosis factor inhibitor. All papers reviewed were from 1999 to 2017 and were written in English. In this article, use of conventional synthetic DMARDs (csDMARDs), bDMARDs and special consideration to be taken upon initiation of biologic therapies in RA will be reviewed.

Keywords: Biologic therapy, Non-tumor necrosis factor inhibitors, Precaution, Prescreening, Rheumatoid arthritis, Tumor necrosis factor inhibitor.

(C) 2018 The Authors. Published by Innovare Academic Sciences Pvt Ltd. This is an open access article under the CC BY license (http://creativecommons. org/licenses/by/4. 0/) DOI: http://dx.doi.org/10.22159/ajpcr.2018.v11i11.27953

\section{INTRODUCTION}

Rheumatoid arthritis (RA) is a progressive chronic inflammatory disease with which, if left untreated, 20-30\% of patients would become permanently work disabled within 3 years of diagnosis. It is known to affect $0.5-1.0 \%$ of the adult population worldwide, and the overall prevalence of the disease for the adult population of Asia is reported between 0.2 and $0.3 \%$ [1-3]. This inflammatory autoimmune disease is chronic progressive symmetrical polyarticular joint disease, characterized by progressive destructions of the articular cartilage, bone, and non-articular muscular structures that can cause joint deformities. After a mean follow-up of 3.9 years, $47.5 \%$ of RA patients experienced at least one extra-articular or systemic manifestation. New treatment modalities by the initiation of targeted biologic therapies are recommended to for disease control, damage prevention, persevering affected joint function, increase in patients' quality of life, and increase the possibilities to achieve complete remission of the disease [4]. The biologic disease-modifying antirheumatic drugs (bDMARDs) or known as the monoclonal antibody $(\mathrm{mAb})$ therapies, which target directly to the specific cytokines cells and molecules of the disease pathophysiology, can be initiated either alone as monotherapy or as combination therapy with the conventional synthetic DMARDs (csDMARDs) therapy within the first 3 months of early RA diagnosis [5-7]. This review will provide an overview of the RA disease, the use of new $m A b$ therapies in addition to the csDMARDs used in the management of RA, as well as suggestive prescreening test based on disease history or concurrent condition on selection of biologic treatment initiation in RA patient.

\section{METHODOLOGY}

Relevant articles were searched in Medline database through PubMed using medical subject headings terms and keywords: RA, bDMARDs, special consideration, tumor necrosis factor inhibitor, and non-tumor necrosis factor inhibitor. All papers reviewed were written in English, from 1999 to 2017. The articles focused on descriptive information on RA disease, treatment used in the management of RA including biologic $\mathrm{mAb}$ and prescreening on biologic treatment initiation.

\section{OVERVIEW ON INCIDENCE OF RA}

RA is a chronic autoimmune disease causing permanent disability that reduces patients' quality of life overtime of the disease progression. RA is known to affect $0.5-1.0 \%$ of the adult population worldwide [1]. RA is more prevalent in females than males with female-to-male ratio of 3:1 and with increasing age [8]. Studies have shown that the incidence of RA remained stable or increased over time, and the prevalence of RA is high in the general population [9]. Known as a multifactorial heterogeneous disease, RA has different incidence rate and prevalence across different populations and geographical area [2,3]. Studies on prevalence and incidence rates of RA in population of Asia consisting countries from Japan, China, Taiwan, Indonesia, and Philippine reported a prevalence of the disease between 0.2 and $0.3 \%$ [2]. It was observed that the prevalence of RA varies widely from population to population with the highest rate found among Pima Indians (5.3\%) and Chippewa Indians (6.8\%) and lowest rate in Asian countries. Prevalence among population from China and Japan is $0.2-0.3 \%$ [10]. The regional variation of RA prevalence may suggest role of genetic factor underlying susceptibility to the disease. In Malaysia, according to the Arthritis Foundation Malaysia 2007, RA affects 5 in 1000 Malaysians. The Rochester Epidemiology Project provides the most recent US data on the incidence of RA. It is observed that in a period of time from 1995 to 2007, it was estimated 1.5 million of the United States (US) adults age more than 18 years old had RA and the RA incidence increased among women compared to men [8]. Published data showed that prevalence rate of RA is generally 2-3 times higher in female than male, and the prevalence increases with increasing age up to about eighth decade of life and peaks at around age of sixties. The incidence peaked earlier for women than men at about ages 55-64 years for women, compared with 75-84 years for men $[11,12]$.

\section{Pathogenesis and extra-articular manifestation of RA}

Basically, the first affected joint structure in RA is the synovium. Synovium is the synovial membrane lines within the joint capsule and produces the synovial fluid. The inner layer of the synovial membrane consists of two synoviocytes which are the macrophage-like 
synoviocytes and fibroblast-like synoviocytes, and both are capable of expressing cytokines and degenerative enzymes. In the case of joint inflammation, the inflammatory arthritis leukocytes migrate from the blood vessels into the synovial lining and trigger release of inflammatory mediators and enzymes by cellular interactions. This synovial immunologic process and inflammation will lead to synovitis, irreversible damage to the cartilage and bone and contributes to systemic consequences of the disease $[1,13]$

It is suggestive that the development of RA is related to trauma, degeneration, abnormalities in biochemical pathways, autoimmunity, inflammation, and genetic polymorphisms. Environmental factors were found to trigger the disease, as well as social factors [13]. The interaction of genetics and environmental factors such as cigarette smoking, infection, or trauma can cause a breakdown of immune tolerance and synovial inflammation in a characteristic symmetric pattern [10]. The T-cells, B-cells, and coordinated interaction of proinflammatory cytokines play important roles in the pathophysiology of RA. CD4 T-cells are activated to secrete interleukin (IL)-2 and interferon gamma (tumor necrosis factor [TNF]- $\gamma$ ) for infiltration into the synovial membrane. These cells later activate synovial macrophages and fibroblasts and hence lose responsiveness to T-cell activities in the course of RA. The B-cells may serve as antigen- presenting cells, together with the production of autoantibodies such as rheumatoid factors. Autoantibodies can form larger immune complexes that can further stimulate pro-inflammatory cytokines, TNF- $\alpha$ through complement, and Fc-receptor activation [14].

Cells of innate immune system including macrophages, neutrophils, and mast cells also play a pivotal role in pathophysiology of synovial inflammation in RA. Neutrophils that present in synovial fluid will synthesize inflammatory prostaglandins, proteases, and reactive oxygen intermediates. Besides macrophages involvement in osteoclastogenesis, macrophages also secrete pro-inflammatory cytokines such as TNF- $\alpha$, IL-1, and IL-6. These cytokines are key mediators of cell migration and inflammation in RA. TNF- $\alpha$ activates cytokines, chemokine expression, endothelial cell adhesion molecules, protects fibroblast, promotes angiogenesis, and suppresses regulatory T-cells. Whereas, IL-6 promotes leukocyte activation, autoantibody production, contributes to anemia, and dysregulation of lipid metabolism. Both TNF- $\alpha$ and IL-6 will amplify osteoclast activation and differentiation [10].

Although RA primarily affects the joints, the disease process can involve other organ systems. Involvement of other organ systems is defined as extra-articular manifestation involving systemic effects or all conditions and symptoms which are not directly related to the locomotor system $[13,15]$. A retrospective analysis done by Hochberg et al. on the incidence and prevalence of extra-articular and systemic manifestations in a cohort of newly diagnosed patients with RA in the US, $47.5 \%$ of 16,752 patients with RA experienced at least one extra-articular or systemic manifestation with a mean follow-up of 3.9 years diagnosis [16]. Extra-articular manifestations identified were rheumatoid nodules, vasculitis, pericarditis, keratoconjunctivitis sicca, uveitis, Felty's syndrome, scleritis, pericarditis, and rheumatoid lung disease [17]. Whereas, for systemic manifestations identified include non-specific features such as asthenia, fatigue, muscle weakness, fever, anorexia, anemia, osteoporosis, weight loss, acute-phase protein production, cardiovascular disease (CVD), and depression [18].

Epidemiologic studies of comorbidities and extra-articular manifestations in RA patients have emphasized that both were associations and predictors to increased morbidity and premature mortality in RA patients [19-21]. A cross-sectional, international, and multicenter study, COMORA (Comorbidities in RA) of 3920 RA patients recruited from 17 countries on five different continents, revealed high prevalence associated comorbidities were psychiatric disorder, mainly depression, gastrointestinal diseases, pulmonary diseases, especially chronic obstructive pulmonary disease (COPD) and asthma, ischemic CVD, hepatitis $\mathrm{B}$, and hepatitis $\mathrm{C}$ infections, and solid malignancies, excluding basal cell carcinoma [22]. When compared to RA patients without extra-articular manifestation, the RA patients with extra-articular manifestation had higher mortality rates of 2.5 (95\% CI: 1.4-4.0) [23]. A study by Norton et al. have shown on average, RA patients had $0.9 \%$ comorbidities at baseline (95\% CI 0.8-1.0\%), and after 5 years from diagnosis increases to 1.8 (95\% CI 1.6, 1.9) and 2.3 (95\% CI 2.1, 2.5) after 10 years. With the increasing comorbidities in RA patients, this study has found that comorbidity impacts on mortality, functional and work disability, but not on structural damage or disease activity of RA patients [24].

\section{OVERVIEW OF TREATMENT IN RA}

According to the European League Against Rheumatism (EULAR) recommendations for the management of RA with synthetic and bDMARDs on the 2016 updates, on classifying the DMARDs, the task force adhered to the previously proposed new nomenclature of DMARDs as tabulated in Table $1[5,25]$. The new nomenclature of the DMARDs provides mechanistic distinction based on the drugs mechanism of action. The chemical compounds of the conventional synthetic DMARDs (csDMARDs), are small molecules that can enter the cell and interact

Table 1: The nomenclature types of treatments for RA

\begin{tabular}{|c|c|c|c|}
\hline DMARDs & & & \\
\hline sDMARDs & & bDMARDs & \\
\hline csDMARDs & Targeted sDMARDs & Biological originator DMARDs & Biological biosimilar DMARDs \\
\hline Methotrexate & Tofacitinib & TNF-TNFi & \\
\hline & & Adalimumab & \\
\hline & & Certolizumab & \\
\hline & & Etanercept & \\
\hline & & Golimumab & \\
\hline & & Infliximab & \\
\hline Leflunomide & Baricitinib & Costimulation inhibitor & \\
\hline Sulfasalazine & & IL-6 receptor inhibitor & \\
\hline & & Tocilizumab & \\
\hline & & Sarilumab & \\
\hline & & Clazakizumab & \\
\hline & & Sirukumab & \\
\hline Hydroxychloroquine & & Anti-B-cell agent & \\
\hline Gold salts & & Rituximab & \\
\hline
\end{tabular}

DMRDs: Disease-modifying antirheumatic drugs, RA: Rheumatoid arthritis, TNF: Tumor necrosis factor, TNFi: Tumor necrosis factor inhibitors, csDMARDs: Conventional synthetic disease-modifying antirheumatic drugs, sDMARDs: Synthetic disease-modifying antirheumatic drugs, bDMARDs: Biologic disease-modifying antirheumatic drugs, IL-6: Interleukin-6 
with the intracellular structures. Whereas, the targeted biological agents, either the targeted synthetic DMARDs (tsDMARDs) or the Biological Originator DMARDs and Biosimilar DMARDs, are engineered to target specifically well-defined functional moiety either as inhibitor of a signal transduction pathways or activate sites on extracellular or cell membrane molecules [25].

\section{csDMARDs therapies in RA}

The goal of therapy in managing RA is mainly to control disease activity, reduce joint damage, and improve patients' quality of life. Earlier treatment modalities for RA, in the 1980s, start with giving support through physical therapy and non-pharmacological interventions. Later, pharmacological interventions are initiated with the use of aspirin and other nonsteroidal anti-inflammatory drugs (NSAIDs) for symptomatic control, followed with a single antirheumatic agent or the DMARDs [26]. However, in the 1990s, it was found that after 1 year early intervention with DMARDs, treatment and management of RA was more effective in terms of slowing down disease progression as compared to treatment with NSAID alone [27]. DMARDs were then known as an agent that was able to suppress the acute phase responses, inhibit joint destruction, and reduce autoantibody levels in RA. Inverting the therapeutic pyramid in managing RA was proposed as the new approach at that time to start using DMARDs as early as possible or at a disease duration of $<6$ months. The first 6 months of RA disease is established as a window of opportunity for treatment given to benefit and effective in controlling disease progression at long term [28,29].

Better clinical outcomes are achieved with suppressing disease progression with early DMARD intervention rather than following the previous pyramid approach [30]. The treatment approach used in RA patient was maintained for long periods of time $[4,26,31]$. Available csDMARDs are gold salts, methotrexate (MTX), sulfasalazine, chloroquine, hydroxychloroquine (HCQ), leflunomide (LEF), cyclosporine-A, azathioprine, d-penicillamine, and minocycline. DMARDs were previously termed as slowly acting antirheumatic drugs due to their relatively long treatment effect or lag time that occurs only after 3-6 months on starting the medication [32]. To overcome lag time of DMARD to take effect, glucocorticoid, a strong anti-inflammatory agent or an analgesic medication is required as a bridging therapy for at least 4-6 weeks duration, to rapidly control inflammation, pain, and associated symptoms during RA disease flares [33].

Apart from the inversion of the pyramid for the treatment management of RA, combination of DMARDs is one of the recommendations for patients with symptomatic early RA suggested in the American College of Rheumatology (ACR) guideline for the treatment of rheumatoid arthritis [34]. Combination therapy was long discussed in the late 1990s due to evidence in long-term failure of using single-drug therapy despite early intervention with DMARDs in RA. The purpose of combination therapy is mainly to increase drug efficacy and minimize risk of drug toxicities using DMARDs targeting different site and mechanism of action. Selection of doses in combining therapy either in double or triple therapy depends either to decrease drug toxicity using lower doses of toxic DMARD drugs or using higher doses of toxic DMARDs or drugs to diminish active RA disease [31]. Combination of DMARDs either as a double or triple therapy most commonly includes MTX as the dominant or anchor DMARD that shows good efficacy with tolerable toxicity [35], slow down radiological damage, and reduce RA mortality [26]. According to the 2015 update of the 2008 ACR recommendations for the use of DMARDs and biologic agents in the treatment of RA, examples of double therapy are MTX + HCQ MTX + LEF, MTX + sulfasalazine (SSZ), and SSZ + HCQ. Whereas, for triple therapy of csDMARDs is MTX + HCQ + SSZ [36]. These combinations of DMARDs are recommended for early RA patients with moderate or high disease activity accompanied with poor prognosis features, as well as the established RA patients with low or moderate to high disease activity with poor prognosis features to achieve complete remission. Recent updates in the management of early RA and established RA permit the combination with a biologic therapy either a TNF inhibitors (TNFi) or a non-TNFi, either with or without MTX based on the agreement of the expert panels on the superior efficacy of treatment combination over a biologic monotherapy [25,34]. MTX in known to exhibit synergistic effect when used in combination with other csDMARDs or bDMARDs specifically the TNFi and IL-6 inhibitor which also suggests reduced of immunogenicity effect of the biologic therapy [37-39].

\section{bDMARDs therapies in RA}

The emergence of biologic targeted therapies in the management of RA has shift the current practice of RA managed care for tight control and treatto-target approach. bDMARDs have shown evidence in improving signs and symptoms of the disease, positive radiological progression, improve patient-reported outcomes in terms of gaining higher quality of life, and achieving disease remission or low disease activity [29,40]. However, RA in acknowledge as a disease that acquires high cost in terms of medication procurement and availability when biologic therapies or new treatment modalities are added to patients' treatment regimen. Therefore, in accordance to the latest 2016 updates in the EULAR recommendation for the management of RA, treatment of RA patient should aim at the best care and based on shared decision between the patient and health-care practitioner, specifically the rheumatologist. Selection of treatment in managing RA should be based on disease activity, progression of structural damage, comorbidities, and safety issues [25].

Biologics are large molecule, protein-based drugs targeting and identifying the cell subsets, and cytokines causing inflammatory and destructive components in RA. Cytokines modulation of rheumatoid synovitis is either the inhibition of the dominant pro-inflammatory cytokines such as the TNF- $\alpha$, IL-1, IL-6, and IL-15 or the augmentation of the inadequate antiinflammatory activity of certain cytokines or naturally occurring cytokines inhibitors. Currently, there are several types of biologic approved for RA. The classification of these biologics depends on which target molecules in their mechanism of actions as listed in Table 2.

\section{TNFi}

The TNF- $\alpha$ is one of the proinflammatory cytokines which is the mediators of inflammation in RA. It is produced by macrophages, T-cells, mast cell, the natural killer cells, fibroblast, adipocyte, and the dendritic cells. It is usually inactive but can be induced by bacteria, viruses, tumor cells, trauma, and other exogenous stimuli through posttranscriptional regulation of gene expressions. When in high concentrations of TNF- $\alpha$, it may lead to inflammation and organ injury [41]. The TNF- $\alpha$ is a trimeric molecule with two bioactive forms, membrane-bound TNF- $\alpha$ and soluble TNF- $\alpha$. It is mediated through two types of receptors which are the TNF receptor 1 (TNFR1) and TNFR2. TNFR1 is expressed on most cells except the endothelial and hematopoiesis cells which are expressed by the TNFR2. The TNF- $\alpha$ or known as the soluble TNF (sTNF) activation is mediated through two pathways either by the activation of nuclear factor-kappa B (NF-kB) cells or the caspase-8-dependent apoptosis or the caspase-3-dependent apoptosis. The activation of the NF-kB acts as the transcriptional activators and induces the transcription factors can induce other inflammatory cytokines, namely the IL-6, IL-8, synergize with interferons, and T-cells activation causing inflammation $[41,42]$. Blockade of the excessive cytokines TNF- $\alpha$ is beneficial to halt inflammation and prevent immune activation in RA disease.

Currently, there are five TNFi for the treatment of RA, approved by the Food and Drug Administration and the European Medicines Agency. The TNFi are the infliximab, adalimumab, etanercept, golimumab, and certolizumab [43]. Infliximab is a chimeric $\mathrm{mAb}$ with the variable region or fragment antigen binding (Fab') of mouse origin and the Fc region of human origin. Whereas, adalimumab and golimumab are fully humanized IgG1 TNFi mAbs. Infliximab, adalimumab, and golimumab are IgG1 antibodies that are capable for complement fixation and receptor binding at constant region $(\mathrm{Fc})$. The three biologic agents bind both the transmembrane TNF (tmTNF) and the sTNF. Certolizumab which is a humanized Fab' fragment bound to polyethylene glycol (PEG) without the Fc region and has higher binding affinity for TNF- $\alpha$. The PEG component reduces immunogenicity, not causing antibody-dependent cell-mediated cytotoxicity, and prolongs its pharmacological availability in the system [42,44]. Etanercept is a 
fusion protein composed of human TNFR2 fused to the Fc region of the human IgG1. It is the only TNFi that can bind and neutralize both TNF- $\alpha$ and a ligand of the lymphotoxin family. Etanercept binds and inactivates sTNF but not the tmTNF $[41,42,44]$. Pharmacokinetic characterization for TNFi is presented in Table 3 .
Non-TNFi

The 2013 update of the EULAR recommended the use of non-TNFi bDMARDs, in cases of RA patients responding insufficiently to MTX and/or other csDMARD strategies, with or without glucocorticoids or the TNFi bDMARDs, and should be commenced with MTX to reduce

Table 2: Biologic therapies used in the treatment of RA

\begin{tabular}{|c|c|c|c|c|}
\hline Biologic agent & Type & Mechanism of action & Available route & Suggested dose \\
\hline Infliximab & $\begin{array}{l}\text { Chimeric antibody Fab' } \\
\text { domain mouse origin, Fc } \\
\text { domain human origin }\end{array}$ & Inhibit TNF- $\alpha$ & Intravenous (IV) & $\begin{array}{l}3 \mathrm{mg} / \mathrm{kg} \text {, infusion at week } 0,2,6 \text {, } \\
\text { then every } 8 \text { weeks }\end{array}$ \\
\hline Adalimumab & $\begin{array}{l}\text { mAb fully human igG1 } \\
\text { antibodies }\end{array}$ & Inhibit TNF- $\alpha$ & Subcutaneous (SC) & $\begin{array}{l}\text { SC } 40 \text { mg every } \\
2 \text { weeks (fortnightly) }\end{array}$ \\
\hline Golimumab & $\begin{array}{l}\text { mAb fully human IgG1 } \\
\text { antibodies }\end{array}$ & Inhibit TNF- $\alpha$ & $\begin{array}{l}\text { Subcutaneous (SC)/ } \\
\text { intravenous (IV) }\end{array}$ & SC 50 mg monthly or 4 weekly \\
\hline Etanercept & $\begin{array}{l}\text { Recombinant protein (TNF } \\
\text { receptor p75-Ig) fusion } \\
\text { protein between human IgG1 } \\
\text { Fc tail and TNF receptor }\end{array}$ & Inhibit TNF- $\alpha$ & Subcutaneous (SC) & SC 50 mg weekly \\
\hline Sarilumab & $\mathrm{mAb}$ & IL-6 receptor blocker & Subcutaneous (SC) & $\begin{array}{l}\text { SC } 200 \text { mg once every } 2 \text { weeks or } \\
\text { fortnightly }\end{array}$ \\
\hline Rituximab & Anti-CD20 mAb & $\begin{array}{l}\text { Block CD20 B-cell, depletes } \\
\text { B-cells but not plasma cells up } \\
\text { to } 6-12 \text { months }\end{array}$ & Intravenous & $\begin{array}{l}\text { IV infusion } 1 \mathrm{~g} \text { at day } 0 \text { and day } \\
14 \text { given } 6-12 \text { months } \\
\text { Confirmed in RA seropositive for } \\
\text { RF and/or anti-CCP antibodies }\end{array}$ \\
\hline Abatacept & $\begin{array}{l}\text { Recombinant } \\
\text { protein - cytotoxic T } \\
\text { lymphocyte antigen } 4 \\
\text { immunoglobulin (CTLA4-Ig) }\end{array}$ & $\begin{array}{l}\text { T-cell costimulation blocker } \\
\text { Block interaction between } \\
\text { CD80 and CD86 on } \\
\text { antigen-presenting cells and } \\
\text { CD28 ligands on T-cells }\end{array}$ & $\begin{array}{l}\text { Intravenous (IV)/ } \\
\text { subcutaneous (SC) }\end{array}$ & $\begin{array}{l}\text { IV infusion initial dose give at } 2 \\
\text { and } 4 \text { weeks, then every } 4 \text { weeks } \\
\text { IV dose based on weight: } \\
<60 \mathrm{~kg}=500 \mathrm{mg} \\
60-100 \mathrm{~kg}=750 \mathrm{mg} \\
\text { More than } 100 \mathrm{~kg}=1000 \mathrm{mg} \\
\text { SC } 125 \mathrm{mg} \text { weekly }\end{array}$ \\
\hline Tofacitinib & JAK inhibitors & $\begin{array}{l}\text { JAK1 and JAK } 3 \text { inhibitor, } \\
\text { interfering with the JAK-STAT } \\
\text { signaling pathway }\end{array}$ & Oral (PO) & PO 5 mg twice daily (BD) \\
\hline Baricitinib & JAK inhibitors & $\begin{array}{l}\text { Selective JAK1 and JAK2 enzymes } \\
\text { inhibitor, interfering with the } \\
\text { JAK-STAT signaling pathway }\end{array}$ & Oral (PO) & PO 4 mg once daily (OD) \\
\hline
\end{tabular}

Table 3: Characterization of TNFi

\begin{tabular}{|c|c|c|c|c|c|}
\hline TNFi & Infliximab & Adalimumab & Golimumab & Certolizumab & Etanercept \\
\hline Abbreviation & IFX & ADA & GOL & CER & ETA \\
\hline Type of agent & Immunosuppressive agents & & & & \\
\hline Structure & $\begin{array}{l}\text { Chimeric Mab Fab' domain of mouse } \\
\text { origin and Fc region of human origin }\end{array}$ & Fully Human & Fully Human & $\begin{array}{l}\text { Humanized Fab' } \\
\text { fragment PEGylated }\end{array}$ & $\begin{array}{l}\text { Fusion protein between } \\
\text { human IgG1 at Fc } \\
\text { region and TNFR2 }\end{array}$ \\
\hline Binding site & Specifically bind TNF- $\alpha$ & & & & $\begin{array}{l}\text { Binds both TNF- } \alpha \text { and } \\
\text { TNF- } \beta \text { (lymphotoxin) }\end{array}$ \\
\hline $\begin{array}{l}\text { Peak plasma } \\
\text { concentration }\end{array}$ & & 5-6 days & 2-7 days & $2-6$ days & $1-2$ days \\
\hline Half-life & Intravenous (IV) infusion: 7-10 days & $\begin{array}{l}\text { Subcutaneous } \\
\text { (SC): } 15-19 \text { days }\end{array}$ & $\begin{array}{l}\text { Subcutaneous } \\
\text { (SC): } 14 \text { days }\end{array}$ & $\begin{array}{l}\text { Subcutaneous } \\
\text { (SC): } 11 \text { days }\end{array}$ & $\begin{array}{l}\text { Subcutaneous } \\
\text { (SC): } 3-5 \text { days }(68 \mathrm{~h})\end{array}$ \\
\hline
\end{tabular}

TNF: Tumor necrosis factor, Mab: Monoclonal antibody, Fab': Fragment antigen-binding, IgG1: Immunoglobulin G1, TNFR2: Tumor necrosis factor receptor 2,

IV: Intravenous, SC: Subcutaneous 
Table 4: List of screening based on disease history or concurrent condition on biologic treatment selection or initiation for RA patient

\begin{tabular}{ll}
\hline $\begin{array}{l}\text { Disease history or concurrent } \\
\text { condition }\end{array}$ & $\begin{array}{l}\text { Laboratory test/suggestion on vaccination } \\
\text { TBC signs and symptoms }\end{array}$ \\
$\begin{array}{ll}\text { Tuberculin skin test/Mantoux test interferon-gamma } \\
\text { release assays (IGRAs) test } \\
\text { Tuberculin skin test/Mantoux test Interferon-gamma } \\
\text { release assays (IGRAs) test }\end{array}$ \\
History of malignancy & Duration of disease more or equal to 5 years
\end{tabular}

Human immunodeficiency virus (HIV) test

Varicella zoster or Herpes zoster Vaccination history

child-bearing age)

Heart failure symptoms

Demyelinating disorder

Hepatitis B

Transaminitis

Baseline inflammatory markers

Other baseline laboratory tests
Close monitoring of viral load and cluster of differentiation antigen 4 (CD4) count

Varicella zoster virus antibody test

Killed vaccines

Pneumococcal vaccination:
Pneumococcal
vaccine (13-valent)
Pneumococcal
vaccine (23-valent)
Influenza vaccination

Hepatitis B vaccination

Recombinant vaccine

Human papillomavirus (HPV) vaccination

Live attenuated vaccine Herpes zoster vaccination

Pregnancy test

Electrocardiography (ECG)

Example of disorders:

Multiple sclerosis

Optic neuritis

Transverse myelitis

Guillain-Barre' syndrome (GBS)

Hepatitis B surface antigen (HBsAg)

Antibody to hepatitis B surface antigen (anti-HBs)

Antibody to hepatitis B core antigen (anti-HBc)

Liver function test (LFT)

Erythrocyte sedimentation rate (ESR)

C-reactive protein (CRP)

Full blood count (FBC)

Fasting blood sugar (FBS)

Renal profile

Lipid profile
Advice on treatment selection

Provide TBC (TB) treatment on confirmation of active TB

Provide TB prophylactic treatment with isoniazid on suspected latent TBC infection

Initiate biologic if solid malignancies or NMSCs have been treated for more than 5 years Caution needed if malignant disease has been treated within 5 years

Tumor necrosis factor inhibitor (TNFi) should be used after weighing the benefit to risk ratio for HIV-positive patients

Non-TNFi to be used cautiously

Contraindicated in active zoster infection

Recommended before initiating biologic therapy or currently on biologic therapy

Recommended before initiating biologic therapy or currently on biologic therapy Annual vaccination

Recommended in high risk of hepatitis presented (intravenous drug abuse, multiple sex partners in previous 6 months, health-care personnel)

Recommended before initiating biologic therapy or currently on biologic therapy

Recommended before initiating biologic therapy. Not recommended for TNFi and non-TNFi biologics currently on biologic therapy Teratogenic risk: Data insufficient to claim safety Limited human data

Animal data suggest low risk

Contraindicated if use in combination with MTX TNFi contraindicated in congestive heart failure or in moderate-to-severe heart failure (NYHA class III-IV, $\mathrm{EF}<50 \%$ )

TNFi contraindicated

Continue immunosuppressive treatment as recommended in patients without this condition Safe to use in combination with effective antiviral therapy or prophylactic antiviral therapy Close monitoring in elevated aminotransferase three times the upper limit of normal (ULN) Discontinue if aminotransferase increased 5 times the ULN On treatment initiation and every follow-up visit

Before and during TNFi treatment within $1^{\text {st }}$ month of treatment initiation and repeated 2 to 3 months during treatment.

To perform on each infusion, infliximab-treated patients.

IGRA: Interferon-gamma release assays, TB: Tuberculosis, CD4: Cluster of differentiation antigen 4, TNFi: Tumor necrosis factor inhibitor, HIV: Human immunodeficiency virus, HPV: Human papillomavirus, MTX: Methotrexate, ECG: Electrocardiography, NYHA class: New York Heart Association Functional Classification, EF: Ejection fraction, HBsAg: Hepatitis B surface antigen, Anti-HBs: Antibody to Hepatitis B surface antigen, Anti-HBc: Antibody to Hepatitis B core antigen, LFT: Liver function test, ULN: Upper limit of normal, ESR: Erythrocyte sedimentation rate, CRP: C-reactive protein, FBC: Full blood count, FBS: Fasting blood sugar

treatment failure due to immunogenicity issues [5]. Non-TNFi when given in combination with MTX had shown improvements in RA signs and symptoms, physical function, health status, and progression of joint damage, therefore, are useful alternatives in patients with long-standing RA who have an inadequate response to TNFi [39]. The non-TNFi approved for the treatment of RA include abatacept, a T-cell inhibitor, 
tocilizumab, an IL-6 inhibitor, rituximab, a B-cell indicator, anakinra, an IL-1 inhibitor, tofacitinib, janus kinase inhibitor, and secukinumab, a fully human antihuman IL-17A mAb.

\section{SPECIAL CONSIDERATION IN USING BDMARDS THERAPIES}

Reactivation of latent tuberculosis (TBC) is a well-known fact in TNFi usage. The occurrence of latent TBC or the incidence rate ratio is higher in infliximab-treated patient, followed by adalimumab-treated patient as compared to etanercept-treated patient. Proportionate to the incidence of latent TBC per event per 1000 patient-years was reported as $1.5,0.9$, and 0.5 events for infliximab, adalimumab, and etanercept, respectively [45]. The mean onset for the development of TBC was found much more earlier in infliximab which is 12 weeks after initiation, 30 weeks for adalimumab, and a total of 46 weeks for etanercept [46]. All patients in TNFi should be monitored for incidence of latent TBC at least for an annual screening despite initial screening done on initiation of TNFi treatment [47].

Based on the observational databases available for incidence of malignancy or cancer in RA patient treated with biologic TNFi, lymphoma and non-melanoma skin cancers (NMSCs) were found to have increased risk and risk of frequent incidence in RA patients compared to the general population [41]. A study by Elandt and Aletaha [48] suggested a generic stepwise approach for the management of patients with a rheumatic condition requiring immunosuppressive treatment in the context of a current or past malignancy. At least a minimum of 2 years for a complete remission of a low-risk malignant disease is required before decision on type of immunosuppressive drug to be used in patients with a history of cancer. Whereas, for lymphomas, carcinomas of the breast, prostate, or colon or large symptomatic renal carcinomas of more than $5 \mathrm{~cm}, 5$ years duration of complete remission of the malignancy disease is desirable. Common immunosuppressive drug used in rheumatic patient with a history of cancer are MTX, sulfasalazine, chloroquine, HCQ cyclosporine, and mycophenolate mofetil. Whereas for biologic therapy, the TNFi are used, but caution is needed with close monitoring of risk of cancer development for all immunosuppressive agents selected [48-50].

Stringent patient screening before initiating a bDMARD is required and necessary to the best of effort in avoiding possible infectious complication or malignancy development [51,52]. List of screening based on disease history or concurrent condition and summary on advice, caution to be considered, and recommendation on treatment selection or initiation is simplified as in Table 4. Biologic therapy is large molecular protein structures that can provoke the development of antidrug antibodies (ADAbs) which associated to immunogenicity that can cause loss of response or reduced efficacy of the biologic treatment. Immunogenicity is the development of unwanted immune response against foreign protein introduced to the body system $[43,53]$. Studies have demonstrated that comedication of a biologic with MTX reduces immunogenicity. As an example, by concomitant MTX therapy in the treatment regimen of infliximab, it decreased the development of antibodies against infliximab which delayed reduction of serum infliximab concentrations as well as reducing the incidence of infusion reactions [54-56]. In a study among RA patient, the cumulative incidence of antibody formation was $6 \%$ and 12 patients treated with only adalimumab was found having antibody positive against adalimumab compared to patients with comedication with MTX. Similar to golimumab, without adding MTX to the treatment regimen, 30\% reduction of golimumab serum concentration were found compared to patient received MTX combination with golimumab $[57,58]$.

\section{CONCLUSION}

Emergence of new treatments in managing RA is evidently improved the patients' quality of life and reduced burden or social impact caused by the autoimmune disease. Selection of treatment either using the conventional or bDMARDs should be done appropriately to prevent further progression of bone destruction in patient, achieving remission state with tolerable side effects while on treatment. For long-term safety, risk-benefit evaluation should be done thoroughly before initiation of bDMARD, and frequent monitoring is compulsory to reduce risk of infection and malignancy during commencement of treatment with bDMARDs. In view of the development of immunogenicity or formation of antibodies while on bDMARDs that can cause loss of response or ineffectiveness of treatment, identifying the factors contributing this issue may assist in personalizing bDMARDs selection for each individual RA patient. Incorporating pharmacokinetic measurement of bDMARD trough levels and the ADAb level may suggest a clear treatment strategy or algorithm to overcome issues of bDMARDs non-responsiveness among affected primary and secondary non-responders' RA patients.

\section{AUTHORS' CONTRIBUTION}

Salmi Abdul Razak performed the literature search, synthesized the data, and prepared the manuscript. Assoc. Prof. Dr. Mohd Makmor Bakry and Dr. Adyani Md Redzuan contributed toward revising the article for intellectual content. The manuscript has been read and approved by all the authors.

\section{CONFLICTS OF INTEREST}

The authors declared no conflicts of interest with respect to the authorship and/or publication of this article.

\section{REFERENCES}

1. Firestein GS. Evolving concepts of rheumatoid arthritis. Nature 2003;423:356-61.

2. Alamanos Y, Drosos AA. Epidemiology of adult rheumatoid arthritis. Autoimmun Rev 2005;4:130-6

3. Jalil SF, Arshad M, Bhatti A, Ahmad J, Akbar F, Ali S, et al. Rheumatoid arthritis: What have we learned about the causing factors? Pak J Pharm Sci 2016;29:629-45.

4. Upchurch KS, Kay J. Evolution of treatment for rheumatoid arthritis. Rheumatology 2012;51 Suppl 6:vi28-36.

5. Smolen JS, Landewe R, Breedveld FC, Buch M, Burmester G, Dougados $\mathrm{M}$, et al. EULAR recommendations for the management of rheumatoid arthritis with synthetic and biological disease-modifying antirheumatic drugs: 2013 update. Ann Rheum Dis 2014;73:492-509.

6. Dejaco C, Singh YP, Perel P, Hutchings A, Camellino D, Mackie S, et al. Recommendations for the management of polymyalgia rheumatica: A European league against rheumatism/American college of rheumatology collaborative initiative. Arthritis Rheumatol 2015;67:2569-80.

7. Romão VC, Vital EM, Fonseca JE, Buch MH. Right drug, right patient, right time: Aspiration or future promise for biologics in rheumatoid arthritis? Arthritis Res Ther 2017;19:239.

8. Myasoedova E, Crowson CS, Kremers HM, Therneau TM, Gabriel SE. Is the incidence of rheumatoid arthritis rising? Results from Olmsted County, Minnesota, 1955-2007. Arthritis Rheum 2010;62:1576-82.

9. Minichiello E, Semerano L, Boissier MC. Time trends in the incidence, prevalence, and severity of rheumatoid arthritis: A systematic literature review. Jt Bone Spine 2016;83:625-30.

10. Gibofsky A. Overview of epidemiology, pathophysiology, and diagnosis of rheumatoid arthritis. Am J Manag Care 2012;18:S295-302.

11. Silman AJ, Pearson JE. Epidemiology and genetics of rheumatoid arthritis. Arthritis Res 2002;4 Suppl 3:S265-72.

12. Doran MF, Pond GR, Crowson CS, O'Fallon WM, Gabriel SE. Trends in incidence and mortality in rheumatoid arthritis in rochester, minnesota, over a forty-year period. Arthritis Rheum 2002;46:625-31.

13. McInnes IB, Schett G. The pathogenesis of rheumatoid arthritis. N Engl J Med 2011;365:2205-19.

14. ChoyE.Understandingthedynamics:Pathwaysinvolvedinthepathogenesis of rheumatoid arthritis. Rheumatology 2012;51 Suppl 5:v3-11.

15. Mielants H, Van Den BF. Extra-articular manifestations. Clin Exp Rheumatol 2009;27 Suppl 55:S56-61.

16. Hochberg MC, Johnston SS, John AK. The incidence and prevalence of extra-articular and systemic manifestations in a cohort of newlydiagnosed patients with rheumatoid arthritis between 1999 and 2006. Curr Med Res Opin 2008;24:469-80.

17. Turesson C, Jacobsson LT. Epidemiology of extra-articular manifestations in rheumatoid arthritis. Scand J Rheumatol 2004:33:65- 72 . 
18. Pollard L, Choy EH, Scott DL. The consequences of rheumatoid arthritis: Quality of life measures in the individual patient. Clin Exp Rheumatol 2005;23 5 Suppl 39:S43-52.

19. Gabriel SE, Crowson CS, Kremers HM, Doran MF, Turesson C, O'Fallon WM, et al. Survival in rheumatoid arthritis: A populationbased analysis of trends over 40 years. Arthritis Rheum 2003;48:54-8.

20. Turesson C, O'Fallon WM, Crowson CS, Gabriel SE, Matteson EL. Extra-articular disease manifestations in rheumatoid arthritis: Incidence trends and risk factors over 46 years. Ann Rheum Dis 2003;62:722-7.

21. Vela P. Extra-articular manifestations of rheumatoid arthritis, now. Eur Med J Rheumatol 2014;1:103-12

22. Dougados M, Soubrier M, Antunez A, Balint P, Balsa A, Buch MH, et al. Prevalence of comorbidities in rheumatoid arthritis and evaluation of their monitoring: Results of an international, cross-sectional study (COMORA). Ann Rheum Dis 2013;73:62-8.

23. Turesson C, Jacobsson L, Bergström U. Extra-articular rheumatoid arthritis: Prevalence and mortality. Rheumatology 1999;38:668-74.

24. Norton S, Koduri G, Nikiphorou E, Dixey J, Williams P, Young A. A study of baseline prevalence and cumulative incidence of comorbidity and extra-articular manifestations in ra and their impact on outcome. Rheumatol (United Kingdom) 2013;52:99-110.

25. Smolen JS, Landewé R, Bijlsma J, Burmester G, Chatzidionysiou K, Dougados M, et al. EULAR recommendations for the management of rheumatoid arthritis with synthetic and biological disease-modifying antirheumatic drugs: 2016 update. Ann Rheum Dis 2017;76:960-77.

26. van Vollenhoven RF. Treatment of rheumatoid arthritis: State of the art 2009. Nat Rev Rheumatol 2009;5:531-41.

27. Wilske KR. Inverting the therapeutic pyramid: Observations and recommendations on new directions in rheumatoid arthritis therapy based on the author's experience. Semin Arthritis Rheum 1993;23:11-8.

28. O'Dell JR. Treating rheumatoid arthritis early: A window of opportunity? Arthritis Rheum 2002;46:283-5.

29. Jones G, Nash P, Hall S. Advances in rheumatoid arthritis. Med J Aust 2017;206:221-4.

30. Wee AS, Shahrir M, Redzuan AM. Medication adherence status among rheumatoid arthritis patients. Int J Pharm Pharm Sci 2016;8:3-7.

31. Wilske KR. Remodeling the therapeutic pyramid: Evolving therapeutic strategies for rheumatoid arthritis. Jpn J Rheumatol 1999;9:1-16.

32. van Jaarsveld CH, Jacobs JW, van der Veen MJ, Blaauw AA, Kruize AA, Hofman DM, et al. Aggressive treatment in early rheumatoid arthritis: A randomised controlled trial. On behalf of the rheumatic research foundation Utrecht, the Netherlands. Ann Rheum Dis 2000;59:468-77.

33. Kavanaugh A, Wells AF. Benefits and risks of low-dose glucocorticoid treatment in the patient with rheumatoid arthritis. Rheumatology (Oxford) 2014:53:1742-51

34. Singh JA, Saag KG, Bridges SLJ, Akl EA, Bannuru RR, Sullivan MC, et al. American college of rheumatology guideline for the treatment of rheumatoid arthritis. Arthritis Care Res (Hoboken) 2016;68:1-25.

35. Saeid K, Min LS, Surulivelrajan M, Girish TP. Demographic, clinical characteristics and drug prescription pattern in patients with rheumatoid arthritis in South Indian Tertiary care hospital. Int J Pharm Pharm Sci 2016;8:251-7

36. Singh JA, Furst DE, Bharat A, Curtis JR, Kavanaugh AF, Kremer JM, et al. Update of the 2008 American college of rheumatology recommendations for the use of disease-modifying antirheumatic drugs and biologic agents in the treatment of rheumatoid arthritis. Arthritis Care Res (Hoboken) 2012;64:625-39.

37. Bartelds GM, Krieckaert CL, Nurmohamed MT, van Schouwenburg PA, Lems WF, Twisk JW, et al. Development of antidrug antibodies against adalimumab and association with disease activity and treatment failure during long-term follow-up. JAMA Intern Med 2011;305:1460-8.

38. Jani M, Barton A, Warren RB, Griffiths CE, Chinoy H. The role of DMARDs in reducing the immunogenicity of TNF inhibitors in chronic inflammatory diseases. Rheumatology (United Kingdom) 2014;53:213- 22
39. Genovese MC, Fleischmann R, Kivitz AJ, Rell-Bakalarska M, Martincova R, Fiore S, et al. Sarilumab Plus methotrexate in patients with active rheumatoid arthritis and inadequate response to methotrexate: Results of a phase III study. Arthritis Rheumatol 2015;67:1424-37.

40. Chaabo K, Kirkham B. Rheumatoid arthritis - Anti-TNF. Int Immunopharmacol 2015;27:180-4.

41. Bachmann F, Nast A, Sterry W, Philipp S. Safety and efficacy of the tumor necrosis factor antagonists. Semin Cutan Med Surg 2010;29:35- 47

42. Sedger LM, McDermott MF. TNF and TNF-receptors: From mediators of cell death and inflammation to therapeutic giants - Past, present and future. Cytokine Growth Factor Rev 2014;25:453-72.

43. van Schouwenburg PA, Rispens T, Wolbink GJ. Immunogenicity of anti-TNF biologic therapies for rheumatoid arthritis. Nat Rev Rheumatol 2013;9:164-72.

44. Yanai H, Hanauer SB. Assessing response and loss of response to biological therapies in IBD. Am J Gastroenterol 2011;106:685-98

45. Dixon WG, Watson K, Lunt M, Hyrich KL, Silman AJ, Symmons DP. Rates of serious infection, including site-specific and bacterial intracellular infection, in rheumatoid arthritis patients receiving antitumor necrosis factor therapy: Results from the British society for rheumatology biologics register. Arthritis Rheum 2006;54:2368-76.

46. Rychly DJ, Pharm D, Dipiro JT, Pharm D. Infections associated with tumor necrosis factor- $\alpha$ antagonists. Pharmacotherapy 2005;25:1181- 92

47. Ramos S, Noqueira A, Dias A, Gonçalves A, Gaio A, Duarte R. Tuberculosis screening in patients receiving biological therapy. Acta Reumatol Port 2015;40:234-40.

48. Elandt K, Aletaha D. Treating rheumatic patients with a malignancy. Arthritis Res Ther 2011;13:223.

49. Askling J. Risks of solid cancers in patients with rheumatoid arthritis and after treatment with tumour necrosis factor antagonists. Ann Rheum Dis 2005;64:1421-6.

50. Wolfe F, Michaud K. Biologic treatment of rheumatoid arthritis and the risk of malignancy: Analyses from a large US observational study. Arthritis Rheum 2007:56:2886-95.

51. De Keyser F. Choice of biologic therapy for patients with rheumatoid arthritis: The infection perspective. Curr Rheumatol Rev 2011;7:77-87.

52. Nordgaard-Lassen I, Dahlerup JF, Belard E, Gerstoft J, Kjeldsen J, Kragballe $\mathrm{K}$, et al. Guidelines for screening, prophylaxis and critical information prior to initiating anti-TNF-alpha treatment. Dan Med J 2012;59:1-12.

53. Wolbink GJ, Aarden LA, Dijkmans BA. Dealing with immunogenicity of biologicals: Assessment and clinical relevance. Curr Opin Rheumatol 2009;21:211-5

54. Lecluse LL, Piskin G, Mekkes JR, Bos JD, De Rie MA. Review and expert opinion on prevention and treatment of infliximab-related infusion reactions. Br J Dermatol 2008;159:527-36.

55. Lipsky PE, van der Heijde DM, Clair EW, Furst DE, Breedveld FC, Kalden JR, et al. Infliximab and methotrexate in the treatment of rheumatoid arthritis. N Engl J Med 2000;343:1594-602.

56. Lichtenstein L, Ron Y, Kivity S, Ben-Horin S, Israeli E, Fraser GM, et al. Infliximab-related infusion reactions: Systematic review. J Crohns Colitis 2015;9:806-15.

57. Anderson PJ. Tumor necrosis factor inhibitors: Clinical implications of their different immunogenicity profiles. Semin Arthritis Rheum 2005;34 5 Suppl:19-22.

58. Moots RJ, Xavier RM, Mok CC, Rahman MU, Tsai WC, Al-Maini $\mathrm{MH}$, et al. The impact of anti-drug antibodies on drug concentrations and clinical outcomes in rheumatoid arthritis patients treated with adalimumab, etanercept, or infliximab: Results from a multinational, real-world clinical practice, non-interventional study. PLoS One 2017;12:1-17 